\title{
Usefulness of Swim Tubes to Maintain the Postoperative Supine Position of Sacrococcygeal Sores
}

Kyung Hee Min, Young Min Kim, Hye Kyung Lee

Department of Plastic and Reconstructive Surgery, Nowon Eulji Medical Center, Eulji University School of Medicine, Seoul, Korea

\begin{abstract}
Background: Patients with impaired mobility or quadriplegia often suffer from pressure sores in the dorsal trunk region. Following flap surgery for stage 3 and 4 sacrococcygeal sores, patients are placed in a prone position to avoid direct pressure on the surgical site. This causes considerable discomfort and increases the risk of postoperative pulmonary complications. The present study introduces a novel method using a swim tube to prevent the pressure on the flap while maintaining a posture comfortable for the patient.

Methods: The subjects were 34 patients who underwent flap surgery between 2015 to 2018 at our hospital. Swim tubes were prepared in different sizes based on the size of the surgical site. All 34 patients were given postoperative care including the use of swim tubes to support supine positions. The tube was placed under the body so that the surgical site was positioned over the center of the tube.

Results: For all 34 patients, there was no loss of flap and sores healed well. Postoperative pulmonary complications decreased, and there were no new pressure sores where the patients came in contact with the tubes. Patient satisfaction increased significantly when prone positioning was kept to a minimum.

Conclusion: Postoperative positioning using a readily available and cost-effective swim tube can achieve both objectives of patient comfort and stability of the surgical site, by helping the patient maintain a comfortable position while protecting the surgical site from direct pressure.
\end{abstract}

Keywords: Pressure ulcer; Postoperative care; Surgical flaps

서 론

욕창은 신체의 돌출부에 지속적이거나 반복적인 압력이 가해져서 발생하는 궤양으로, 환자의 전신상태, 영양상태, 체위 등의 영향을 받는다. 특히 의식이나 감각, 운동저하가 있는 환자들은 욕창으로 입원하게 되는 경우가 많으며 재발률이 높아 여러 차례의 수술을 받기도 한다. 외국 에서는 좌골부 욕창이 많으나 우리나라에서는 천골부의 욕창이 많은 것으로 보고되고 있다 [1]. 몸통 배부측 욕창의 피판 수술 후 환자의 체위는 수술 부위가 눌리지 않도록 측와위 또는 복와위를 유지해야 하며, 짧게는 10 일에서 길게는 3 주까지 수술 부위가 눌리지 않는 자세로 유 지되어야 한다[2,3]. 하지만 사람이 침상안정을 취할 때, 복와위보다는 앙와위가 더 편안하다. 따라서 복와위를 유지하면 환자는 그 자체로 큰 불편감을 느끼게 되며 만약 협조가 잘 되지 않 아앙와위를 취하게 되면 수술 부위가 눌리면서 피판의 생존에 악영향을 줄수 있다.

전신마취 수술 후 환자의 체위는 좌위 또는 반좌위를 취하는 것이 수술 후 호흡기계 합병증 의 위험성을 줄인다고 알려져 있다[4,5]. 그러나 배부측 욕창 수술 후 이와는 반대로 복와위를 유지하게 되면 폐렴, 무기폐 등 호흡기계 합병증의 위험성이 증가하게 될 것이다. 게다가 욕창 환자들은 고령에 기저질환이 있는 환자가 많아 복와위를 취할 경우 호흡기계 합병증의 위험성 이 더 높다고 볼수있다.

이에 저자들은 복와위로 인한 환자의 불편감과 호흡기계 합병증의 위험을 감소시키고, 피판
Original Article

Received: July 31, 2019

Revised: August 27, 2019

Accepted: August 28, 2019

Corresponding author: Hye Kyung Lee, M.D., Ph.D.

Department of Plastic and Reconstructive Surgery, Nowon Eulji Medical Center, Eulji University School of Medicine, 68 Hangeulbiseok-ro, Nowon-gu, Seoul 01830, Korea

Tel: +82-2-970-8255

Fax: +82-2-972-0068

E-mail: hklee240@gmail.com

This is an Open Access article distributed under the terms of the Creative Commons Attribution Non-Commercial License (http://creativecommons.org/licenses/by-nc/4.0/) which permits unrestricted non-commercial use, distribution, and reproduction in any medium, provided the original work is properly cited.

C 2019 Korean Wound Management Society 
이 눌리지 않게 하여 피판의 생존율을 높일 수 있도록 고안한 물놀이 튜브 적용법을 소개하고자한다.

\section{방 법}

본원에서 2015년 1월 1일부터 2018년 12월 31일까지 몸통 배부측에 발 생한 3-4기의 욕창에 대해 피판 수술을 받은 34명의 환자를 대상으 로 하였다. 연구는 헬싱키 선언의 원칙에 따라 수행되었으며 본원의 임상시험심사위원회의 승인을 받았다(EMCIRB 19-56). 피판 수술을 받은 환자 34 명 모두에게 물놀이 튜브를 적용하였으며, 물놀이 튜브 는 손잡이 등 장식이 없는 것으로 수술범위에 따라 다양한 크기의 내 경 $(25-45 \mathrm{~cm})$ 으로 준비하였다. 바람은 70\% 정도 주입하여 환자의 체 위에 따른 변동이 가능하도록 하였다. 튜브의 겉면은 탄력붕대로 감 았고, 국소적 압력을 피하기 위해 공기주입부가 침대 면으로 향하도 록 적용하였다(Fig. 1). 수술 후에는 수술 부위가 중앙으로 오도록 물 놀이 튜브를 몸통 밑에 받치고 앙와위를 취하게 하여 수술 후 자세 관리를 하였다(Fig. 2). 앙와위를 취할 때 튜브의 높이로 인해 환자가 불편감이 있는 경우에는 등에 튜브 높이의 반 정도 두께의 베개나 방 석 등을 받쳐 엉덩이, 등, 머리의 높이를 맞춰 주었다. 일반적인 수술 부위 관리에 준하여 주기적인 소독 및 위생관리, 체위변경 등을 하였 으며 수술 후에 발생한 합병증 및 재수술 여부를 확인하였다.

\section{결 과}

본 연구에서 분석한 34 명의 환자는 남자, 여자 각각 18 명, 16 명이었으 며, 환자의 나이는 평균 66.4 세였다. 욕창의 평균 크기는 $7.5 \times 7.2 \mathrm{~cm}^{2}$ 이었으며 평균적인 경과관찰 기간은 2.98 개월이었다. 수술 후 상처 벌 어짐이 3건 있었으며 폐렴이 2건 발생하였다. 재수술은 상처 벌어짐 에 대해 3건이 시행되었으며 모두 재수술 이후 잘 회복되었다(Table
1). 욕창의 위치는 미골부가 $64.7 \%$, 천골부가 $26.4 \%$, 등 부위가 $5.8 \%$, 그리고 둔부가 $2.9 \%$ 였으며 다양한 방법의 피판 수술을 시행하였다 (Table 2). 물놀이 튜브를 적용해 앙와위로 수술 후 자세 관리를 한 환 자 34 명 모두 피판이 소실되지 않고 잘 치유되었다. 튜브에 닿는 면에 새로운 욕창이 발생한 경우는 없었으며, 복와위를 최소화함으로써 환자들의 만족도가 많이 증가하였다.

\section{고 찰}

일반적으로 욕창의 유병률은 $14 \%$ 에서 $17 \%$ 정도로 추산되며[6,7], 욕 창과 관련한 보건의료 비용은 미국에서만 매년 30 억 달러가 넘는 것 으로 알려져 개인과 사회에 큰 부담이 되고 있다[8]. 특히 척추 손상 환자나 뇌혈관사고 환자, 고령의 환자는 대개 부동자세, 피부감각저 하 등이 동반되기에 욕창이 발생할 위험성이 크다. 척추 손상 환자 중 $40 \%$ 에 달하는 비율이 욕창을 겪게 된다고 한다[9-11].

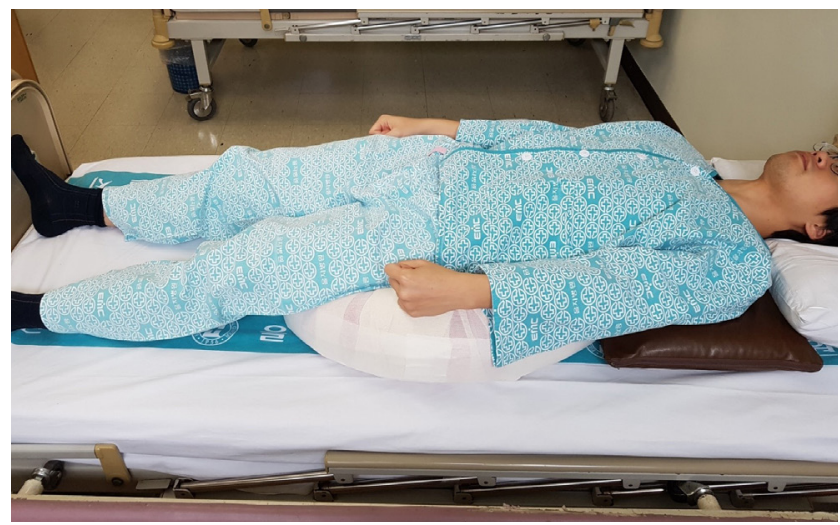

Fig. 2. Example photo of the patient model. Swim tube in position under the sacral sore patient model.
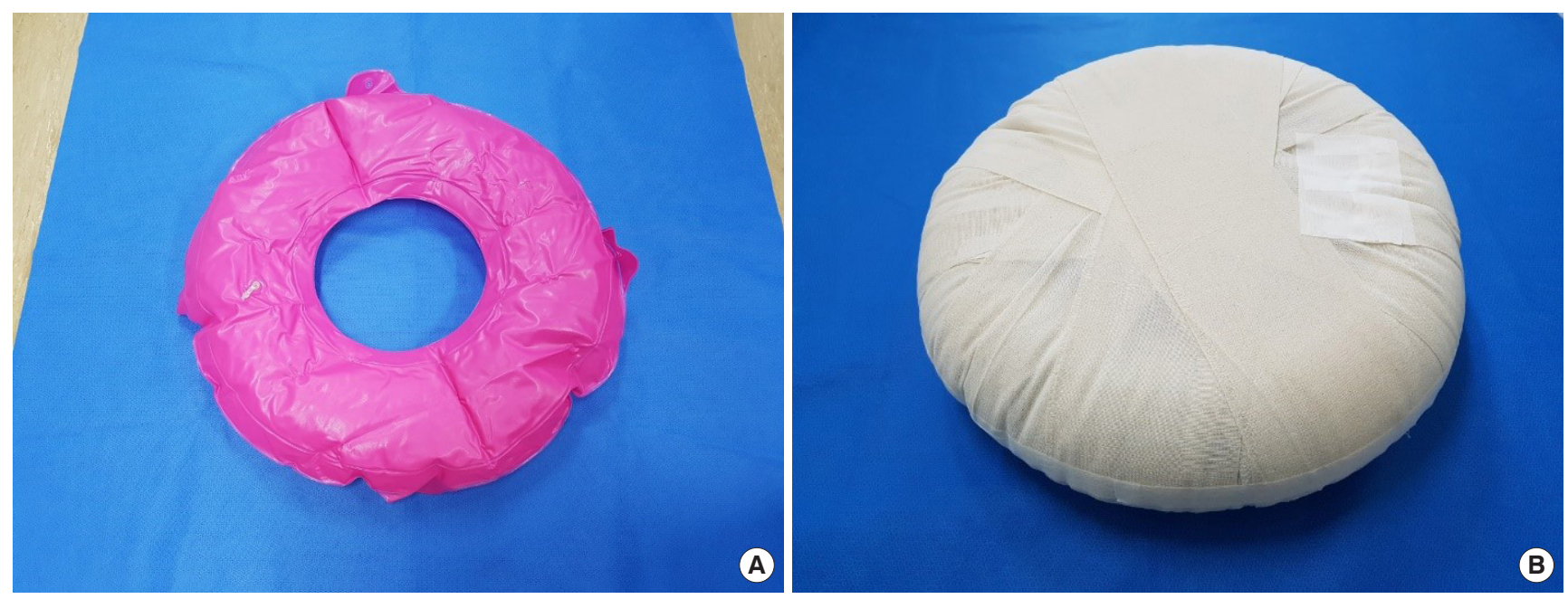

Fig. 1. Photo of the swim tube actually used. (A, B) Swim tube, inflated $70 \%$ and wrapped in elastic bandage, to be used like a hammock. The air valve must face downwards. 
Table 1. Demographics and characteristics of patients involved in study

\begin{tabular}{lc}
\hline Characteristic & Value \\
\hline Sex & \\
Male & $18(52.9)$ \\
Female & $16(47.0)$ \\
Mean age (yr) & $66.4(27-92)$ \\
Mean follow-up period (mon) & $2.98(1-13)$ \\
Mean sore size (cm²) & $7.5 \times 7.2$ \\
Past medical history & \\
Diabetes mellitus & $12(35.2)$ \\
Pneumonia & $8(23.5)$ \\
Cerebrovascular accident & $8(23.5)$ \\
Dementia & $7(20.5)$ \\
Paraplegia & $4(11.7)$ \\
Quadriplegia & $3(8.8)$ \\
Others (ataxia, spine abscess, myelopathy etc.) & $4(11.7)$ \\
Complication & \\
Dehiscence & $3(8.8)$ \\
Pneumonia & $2(5.8)$ \\
Reoperation & $3(8.8)$ \\
\hline
\end{tabular}

Values are presented as number (\%) or mean (range).

욕창을 방치한다면, 만성적인 감염, 패혈증, 대사적 이상 때문에 환 자의 전신적인 컨디션이 악화될 수 있다. 따라서 욕창 발생 시 의료진 모두가 세심하게 주의를 기울여야 하며, 적절한 영양제공 및 2시간마 다 체위변경, 피부가 눌리지 않는지 지속적으로 관찰하는 것이 필요 하다. 1-2기의 욕창에서는 보통 보존적 드레싱으로 치료를 할 수 있 지만, 근육이나 뼈를 침범한 3-4기 이상의 욕창에서는 외과적인 수 술이 필요하며, 특히 몸통 배부측의 척추주위 욕창에서는 변연절제 술 후 광범위한 근육피판, 천공지피판이 주로 이용된다[12].

욕창 수술 시에는 수술과 관련된 합병증뿐만 아니라 수술 후 발생 하는 합병증에 대한 위험성에 대해서도 생각해야 한다. 따라서 욕창 환자의 치료 방침을 결정할 때에 의료진은 어려운 고민에 빠지게 된 다. 특히 욕창은 고령환자에서 발생하는 경우가 많은데, 고령환자에 서 욕창의 수술적 치료 후 $21 \%$ 의 환자에서 수술 후 합병증으로 경증 또는 중증의 폐렴이 발생했다는 대규모 연구도 있었다[13]. 전신마취 수술 후 복와위를 취하면 수술 후 객담배출 및 호흡에 방해가 되어 폐렴, 무기폐 등 호흡기계 합병증의 위험성이 높아지는데 저자들은 수술 후 물놀이 튜브를 이용하여 환자가 앙와위를 취하도록 함으로 써 이러한 호흡기계 합병증을 예방할 수 있었다. 본 연구에서 수술 후 에 폐렴이 발병한 환자 2 명은 수술 전에도 폐렴이 주기적으로 발병했 던 고령환자로 수술과의 연관성보다는 기존의 전신적 상태에 기인한 것으로 보인다.

환자가 편안한 자세를 유지하면서도 수술 부위가 눌리지 않도록
Table 2. Sore-site locations and reconstruction methods $(n=34)$

\begin{tabular}{ll}
\hline Anatomical location \& treatment & No. of case (\%) \\
\hline Coccyx & 22 (64.7) \\
V-Y advancement flap & 16 \\
Local flap & 2 \\
Limberg flap & 1 \\
Rotation flap & 2 \\
Island flap & 1 \\
Sacrum & $9(26.4)$ \\
V-Y advancement flap & 7 \\
Rotation flap & 1 \\
Propeller flap & 1 \\
Back & $2(5.8)$ \\
V-Y advancement flap & 1 \\
Local flap & 1 \\
Buttock & $1(2.9)$ \\
V-Y advancement flap & 1 \\
\hline
\end{tabular}

하기 위해서, 꼭 비싸고 특수한 장치를 구해야만 하는 것은 아니며 일 상생활에서 쉽게 구할 수 있고 비용 효율이 높은 물놀이 튜브를 실제 치료에 적용함으로써 환자의 편안함 및 수술 부위의 안정, 수술 후 합 병증 예방 등 여러 가지 목적을 달성할 수 있었다.

물놀이 튜브를 적용하여 환부에 가해지는 압력을 제거하더라도 튜브에 닿는 면이 지속적으로 압력을 받게 되면 이 부위에 새로운 상 처가 생길 수도 있을 것이다. 또한 피판수술 직후에는 튜브의 압력으 로 피판 주변의 혈류를 방해하여 피판의 부종과 울혈을 일으킬 가능 성도 예상할 수 있을 것이다. 이를 예방하기 위하여 튜브적용 후 주기 적으로 튜브를 눌러줌으로써 튜브 접촉면에 가해지는 지속적인 압력 을 피하고 간헐적인 압력과 이완을 반복하도록 하였으며 피판 주변 의 혈류를 주기적으로 회복해 줄 수 있었다. 결과적으로 튜브가 닿는 면에 상처가 생긴 환자는 없었고 피판의 부종이나 울혈이 발생한 경 우도 없었다. 이는 환자나 보호자가 쉽게 자주 행할 수 있는 행위로서 수술 후 환자와 보호자의 적극적인 치료의지를 고취시키고 향후 욕 창 재발 방지 교육에도 도움이 되었다.

기존의 욕창방지용 도넛형 베개는 지름이 비교적 작고 충전물이 유체가 아닌 작은 고형의 미세입자로 이루어져 간헐적인 압력의 이 완, 압력의 재배치는 가능하지 않았으나 저자들이 사용한 공기가 주 입된 튜브는 이를 가능하게 하였으며 피판의 크기에 따라 다양한 크 기의 튜브를 선택할 수도 있어 편리하다. 또한 수술 후 앙와위인 경우 피판이 중력과 같은 방향에 위치하게 되어 부종과 울혈의 가능성이 클 것으로 예상되나 탄력붕대를 튜브를 가로질러 감게 되면 해먹과 같이 작용하여 피판을 받치는 효과를 얻게 되어 중력의 영향을 보완 할수 있다(Fig. 1).

튜브가 침대에 고정되어 있는 것이 아니고 환자가 침대에서 떠 있 는 상태이기 때문에 체위변경을 시행할 때에 균형을 잃거나 낙상의 
우려가 있을 수 있다. 이를 방지하기 위해 낙상의 위험이 높은 환자는 의료용 시트나 천을 접어 환자의 몸과 튜브 사이에 깔고 시트의 양쪽 을 잡아 환자를 움직여 안전하게 체위변경을 시행하였다. 또 튜브의 표면을 탄력붕대로 감아 마찰력을 확보하였다(Fig. 1). 평상시에는 꼭 가드레일을 올려 환자의 움직임으로 인한 낙상을 예방할 수 있었다.

결론적으로, 저자들은 물놀이 튜브를 수술 후 적용함으로써 환자 자세의 편안함 및 환부의 안정을 얻을 수 있었으며, 수술 후 호흡기계 합병증의 발생률도 낮출 수 있었다. 욕창뿐만 아니라 국소적 압력의 집중을 피해야 하는 다양한 치료에도 물놀이 튜브를 적용할 수 있을 것이라 생각된다.

\section{Conflict of interest}

No potential conflicts of interest relevant to this article are reported.

\section{Acknowledgments}

Kyung Hee Min https://orcid.org/0000-0002-3456-0191

Young Min Kim https://orcid.org/0000-0001-5191-2593

Hye Kyung Lee https://orcid.org/0000-0001-8368-8741

\section{References}

1. Oh KS, Lim SY, Mun GH, et al. The treatment of pressure sore. J Korean Wound Management Soc 2005;1:83-6.

2. Isik FF, Engrav LH, Rand RP, et al. Reducing the period of immobilization following pressure sore surgery: a prospective, randomized trial. Plast Reconstr Surg 1997;100:350-4.

3. Foster RD, Anthony JP, Mathes SJ, et al. Flap selection as a determinant of success in pressure sore coverage. Arch Surg 1997; 132:868-73.
4. Tagaito Y, Isono S, Tanaka A, et al. Sitting posture decreases collapsibility of the passive pharynx in anesthetized paralyzed patients with obstructive sleep apnea. Anesthesiology 2010; 113:812-8.

5. Zaremba S, Mueller N, Heisig AM, et al. Elevated upper body position improves pregnancy-related OSA without impairing sleep quality or sleep architecture early after delivery. Chest 2015;148:936-44.

6. Whittington KT, Briones R. National Prevalence and Incidence Study: 6-year sequential acute care data. Adv Skin Wound Care 2004;17:490-4.

7. Cuddigan J, Berlowitz DR, Ayello EA. Pressure ulcers in America: prevalence, incidence, and implications for the future. An executive summary of the National Pressure Ulcer Advisory Panel monograph. Adv Skin Wound Care 2001; 14:208-15.

8. Fogerty MD, Abumrad NN, Nanney L, et al. Risk factors for pressure ulcers in acute care hospitals. Wound Repair Regen 2008;16:11-8.

9. Sheerin F, Gillick A, Doyle B. Pressure ulcers and spinal-cord injury: incidence among admissions to the Irish national specialist unit. J Wound Care 2005;14:112-5.

10. Benbow M. Pressure ulcer incidence reporting. Nurs Stand 2004;18:57-60.

11. Caliri MH. Spinal cord injury and pressure ulcers. Nurs Clin North Am 2005;40:337-47.

12. Choi EC, Park ES, Kim YB. The treatment of intractable pressure sores using VAC (vacuum assisted closure). J Korean Wound Management Soc 2009;5:50-6.

13. Han HH, Ko JG, Rhie JW. Factors for postoperative complications following pressure ulcer operation: stepwise multiple logistic regression analysis. Int Wound J 2017;14:1036-40. 